\title{
A whole new ball game: How Sky Sports News journalists are learning from the academy
}

\author{
Simon McEnnis \\ Principal Lecturer in Journalism \\ University of Brighton \\ s.mcennis@brighton.ac.uk
}

\begin{abstract}
This article outlines an academic development programme at Sky Sports News (SSN), a 24-hour rolling news television channel in the United Kingdom. The course counters negative industry perceptions of journalism education. It demonstrates that a major news organization and a significant employer of sports journalists in the United Kingdom considers that academia has an important role to play in the professionalization process. SSN's commitment to resourcing such a programme should also be seen as an attempt to raise professional standards and overcome the derogatory 'toy department' reputation that has hampered sports journalism. This article outlines how industry professionals are connected to academic learning and encouraged to critically reflect on their practice. The article intends to raise awareness of the programme across contexts and countries and, in doing so, provides a blueprint for similar industry-academic collaborations.
\end{abstract}

\section{Introduction}

The journalism industry often takes a dim view of academia. For instance, the editor of The Sun newspaper in the United Kingdom, Tony Gallagher, has been quoted as saying at a conference (Ponsford 2016):

There is something that journalists can probably learn from the restaurant trade in that a lot of journalists become consumed by the idea that they are part of a profession and in some sense they are part of an academic discipline...you become a journalist by practising it not by learning it in a classroom.

Further, the discourse of journalism as a trade can lead to a neglect and stagnation in staff development. Former Sun managing editor Graham Dudman was acquitted of all charges after standing trial in 2014 with five other senior Sun colleagues accused of conspiracy to commit misconduct in a public office by paying for stories. When asked during the trial whether there was any journalism training at the newspaper, Dudman (himself now a journalism educator) stated: "None, there was training in relation to management and HR skills, and employment law, but that was it" (Anon 2014).

This epistemological stance of journalism knowledge as experiential is at odds with journalism's transformation to a graduate-entry career within the U.K. over the past 20 years or so, fuelled by the rise in journalism degree courses. Prior to the 1990s, journalism training in the U.K. tended to be the domain of further 
education colleges running year-long skills-based apprenticeship courses for trainees who had left school at 18. Students would then leave college with industry qualifications and quite often find entry-level jobs with the local and regional press. Aldridge and Evetts (2003) argue that undergraduate programmes in journalism have become attractive to universities because of their tendency to attract high student numbers. The authors explain that journalism has been allowed to become a graduate profession in the UK 'in the absence of any industry-wide training strategy' (Aldridge and Evetts 2003: 552). The graduatization of journalism in the UK has therefore meant that 'many journalists now regard themselves not merely as "being professional" but as being a member of a profession' (Aldridge and Evetts 2003: 560).

A dismissive attitude to both journalism education and professionalization is not a universal outlook within the industry. Sky Sports News (SSN) in the UK has been running staff development programmes since 2010 with journalism training high on its agenda. The author of this article was contacted by SSN in 2011 as a practitioner-turned-academic to devise and deliver a training course for industry professionals. The author has a professional background in sports journalism with The Sun newspaper between 2000 and 2009, and local newspapers before that, before moving into academia. This course was mainly aimed at SSN journalists with no prior formal training experience and covered basic writing skills, media law and regulation.

In 2017, SSN decided to deepen its connection to university learning by repositioning the skills training course as an academic development programme. There are three key reasons for this shift. Firstly, SSN's senior editors were satisfied that its workforce had developed the necessary basic skills and competencies to meet organizational needs. Secondly, SSN had become increasingly interested in sports journalism research through its dialogue and discussions with university educators. SSN has developed close links with universities and other journalism providers mainly through its association with UK industry training body, the National Council for the Training of Journalists (NCTJ). SSN executive editor Andy Cairns was the chair of the NCTJ's accreditation board from March 2016 until his retirement in June 2019. The academic development programme is part of a broader portfolio of engagement activities with journalism educators that include a rolling internship placement and graduate employment scheme. Thirdly, SSN recognized that sports journalists' work environment was becoming increasingly complex in terms of technological change and the growing commercialization and globalization of professional sports. Therefore there was a need for journalists to develop the necessary knowledge, awareness and sensitivities to report on sports issues effectively. For SSN, the move to a research-informed programme that encouraged reflective practice through an exploration of contextual and critical issues seemed a logical progression.

The academic development programme can be considered to be groundbreaking within the U.K. news industry in terms of SSN's substantive, sustained, and structured engagement with university journalism education. SSN's transition from a basic skills course to an academic development programme can be 
interpreted within the context of sports journalism's attempts to banish its 'toy department' reputation. The toy department concept relates to sports journalism's low standing within the industry for perceived weak commitments to professionalism (Boyle 2006; Cassidy 2017; Oates and Pauly 2007; Rowe 2007; Salwen and Garrison 1998). These displays of "unprofessional" behaviour include prioritizing subjectivity over objectivity, lacking neutrality at sports events, compromising independence and autonomy by being too close to sources, and sport itself being unimportant and trivial compared to more 'serious' news concerns (Boyle 2006; Rowe 2004, 2007).

This article outlines the academic development programme in this article with a view to stimulating both similar engagement in other contexts and a debate about what industry should and can learn from academia. Such a partnership is an important step in breaking down the barriers between academia and industry. It bucks the trend of an academic-industry relationship that is usually one-sided and defined by employers telling journalism educators what skills they need to teach to make students employable (Ketterer et al 2014).

The programme is also an acknowledgment by a major news company that professionalization is desirable, universities can play an important role in that process and that critical reflection can lead to good journalism practice. This article provides an overview of the curriculum and the learning that takes place. The article will demonstrate how the course has been informed by sports journalism research and provide indicative references. It will then conclude with a critical reflections section that will link the programme to broader conceptual thinking on journalism professionalism.

\section{Background}

SSN is the only 24-hour rolling sports news channel in the United Kingdom but must be accessed with a pay-TV package. SSN has switched from a pay-TV to free-to-air back to pay-TV model since it was launched in 1998. SSN augments and underpins Sky's other sports channels ${ }^{1}$ and both drives and sustains narratives around live events (Sugden and Tomlinson 2010).

The author of this article worked with SSN editorial managers to devise a course that met their changing needs. SSN would continue its consultancy arrangement from the basic skills course to insource the author by buying out time from the university. The academic development programme is delivered to 20 industry professionals on average at Sky each academic year. The cohort is divided into a morning and afternoon group with each industry professional studying 19 sessions of three hours long across the year (course contact hours are 57 per person but with 114 overall hours of delivery). The sessions are discussionbased and take place in conference or training rooms at Sky's headquarters in Isleworth, West London. The course starts at the end of October and takes place fortnightly until March when the sessions move weekly in the build-up to the exam day in early June. Three cohorts have so far completed their studies on the academic development programme as of mid-2019 with another due to begin the course in October 2019. 
The programme culminates in an exam day when candidates must sit two exam papers of 90 minutes each that test they know, understand and can apply the course content. The exams involve a mixed model of questions such as miniessay and applied practice. The NCTJ is the awarding body of the course and issues a qualification called the Certificate in Professional Sports Journalism. Both exam papers need to be passed with a minimum mark of 50 per cent.

The course cohort is drawn from mainly the SSN newsroom but also from related departments, either other sports channels or the digital operation. The candidates occupy broadly journalistic roles across broadcast and digital including, for example, reporter, news editor, sub-editor, producer, and planner. The selection process consists of either industry professionals volunteering to sign up or line managers recommending for the course to be studied as part of a staff development review action plan. A journalist's interest in enrolling is often piqued by a word-of-mouth recommendation from a colleague who has previously studied either the basic skills incarnation or an earlier iteration of the academic development programme. Line managers are expected to facilitate and support their employees' study commitments through careful scheduling of duties and arranging replacement labour in the newsroom during classroom sessions.

The cohort is evenly balanced in gender, which is noteworthy as sports journalism education in the United Kingdom tends to be delivered to predominantly male students. Industry professionals on the course are mainly aged under 40. Educational backgrounds vary with some industry professionals having previously studied journalism degrees, while others have either studied degrees in different subject areas or not being degree qualified at all.

\section{What do Sky Sports News' industry professionals learn?}

The basic premise is that university learning can equip industry professionals to work more effectively in an increasingly complex sports media landscape. There are three broad sections to the course: A critical introduction to sports journalism and media, a critical understanding of the changing digital landscape, and contextual knowledge for sports journalists. This section of the article will explore these themes in greater detail while referencing the academic discussion that informs them.

\section{A critical introduction to sports journalism and media}

Industry professionals are made aware of the historical trajectory of sports media and Sky has played a major role in the evolution of the inseparable relationship between TV and sport (which Wenner (1998) refers to as 'mediasport') within the UK context. The course maps sports media's print origins in the $19^{\text {th }}$ and $18^{\text {th }}$ centuries, the advent of broadcast technologies in the early $20^{\text {th }}$ centuries, and the emergence of digital media in the $21^{\text {st }}$ century (Boyle and Haynes 2009; Hutchins and Rowe 2012; Whannel 1992). From here, TV's role in shaping the commercialized, commodified and globalized sport 
industry is explored. The cohorts reflect upon Sky's pivotal role in driving payTV sport in the UK. For greater detail on this point, Boyle and Haynes' (2004) Football in the New Media Age explores the role of Sky as the broadcast vehicle for the formation of the Premier League in 1992. A crucial aspect of study is the consideration of pay-TV and free-to-air models in sport and the arguments surrounding them (Boyle and Haynes 2009). This discussion gives industry professionals an opportunity to reflect on the impact that their organization has had on sport and society in the UK.

The political economy of sports media is also important in helping the cohort make sense of their rapidly changing organization. Sky plc was taken over by Comcast in 2018 and the possible future direction of the business is discussed. As the outcome of a bidding war with $21^{\text {st }}$ Century Fox to take full control of the company. The UK Government allowed Fox to proceed with its takeover bid providing Sky News was sold to another company to ensure its independence and security and avoid the Murdoch family from having excessive influence over the domestic news industry (Waterson 2018). Candidates consider SSN's position with the wider Sky empire in the context of these developments.

The emergence of new online streaming services such as Amazon Prime builds on this discussion. Amazon has made an impact on the UK sports rights scene in recent years. Its live sport portfolio includes US Open tennis and the ATP World Tour. Amazon Prime is streaming 20 live and exclusive Premier League games from the 2019/20 season. The cohort consider how emerging sports rights players such as Amazon Prime and Netlix pose challenges and potential disruption to Sky's traditional broadcast model.

The groups are then connected with research on sports journalism's occupational status and culture to give them a better understanding of their professional experiences and obligations. An important starting point is to contemplate 'what is journalism for?' In the UK, journalism's societal function is to scrutinise power via its 'fourth estate' function. SSN professionals consider how this principle applies to the sports context, specifically in terms of where power can be located. The groups discuss the cheerleader versus crusader concept (Rowe 2004, 2007; Boyle 2006) in discussing whether journalists have struck the right balance between standing in for sports fans and holding power to account.

The cohorts share good practice of working with media managers and how this relationship can be navigated so that journalists retain their editorial autonomy and independence while maintaining professional distance. Public relations has been identified within the academic literature as a heavily constraining factor on sports journalists' ability to access sportspeople that compromises their autonomy in being able to act freely in the pursuit of stories (Sherwood et al 2017a, 2017b; Sugden and Tomlinson 2007; Suggs Jr 2015). A guest speaker from the public relations industry, usually from a Premier League football club, outlines the media management perspective while the industry professionals express their views of the relationship in an open and frank dialogue. This 
session has grown in importance as sports clubs invest in their own public-facing media operations through their own websites and TV channels.

\section{A critical understanding of the changing digital landscape}

Digital technology has led to shifts in sports journalism practice and publishing (Boyle 2010; English 2011; Hutchins and Boyle 2017; Hutchins and Rowe 2012; Sherwood and Nicholson 2013). Industry professionals are encouraged to reflect upon dramatic shifts in their daily routines that have become increasingly multiplatform and multimedia in character. The groups explore how technology has changed different roles within SSN, such as mobile phones acting as video cameras in field reporting. They also analyze how sports media are increasingly experimenting with mobile technology such as drones, virtual reality, augmented reality and mixed reality. The cohorts consider the ethical and legal implications of using these technologies, such as regulations over drone use in the United Kingdom.

The digital section also explores social media. Here, industry professionals share experiences of good and bad practice. The cohorts have included digitally native journalists, who can give fresh insights into the latest social media developments to colleagues who work in more traditional broadcast roles. A general discussion takes place on wider techno-political developments that are disrupting the mainstream media, such as Fake News, and how journalists can best respond. Ethical considerations related to fact-checking and verification are crucial here while journalists also try and locate what is suitable information to tweet from their personal accounts and how this differs from 'official' newsroom accounts. The cohorts also discuss interactivity with audiences through social media engagement and comments below sports articles. Industry professionals again share experiences and discuss the formal and informal rules of engagement with audiences.

This area of the course also links back to the critical introduction in assessing what digital developments have meant for the toy department reputation (McEnnis 2018b). On the one hand, it can be argued this label has given sports journalists vital room to manoeuvre with digital innovation and experimentation (Morrison 2014). The cohort analyses the outcome of these experiments - such as live blogging and multimedia long-form projects such as Snowfall - and contemplates what they have meant for sports principles and practice (Dowling and Vogan 2015; McEnnis 2016). However, the counter-argument is that sports journalists have dumbed down standards online through the use of clickbait and cannibalization of content that appears elsewhere on the internet (Hutchins and Rowe 2012). Further, previous research has found that online sports journalists lack occupational status compared to more traditional modes (McEnnis 2018b). Do the groups believe that the same problems apply to the Sky Sports operation?

The digital section also encourages industry professionals to develop an in-depth understanding of the changing sport communication landscape. Alternative, nonmainstream models of sports journalism are explored. Blogging is placed in its historical context of fanzines (Haynes 1995) before contemporary examples are 
discussed. Industry professionals consider open models of journalism and collaborative ways of mainstream and non-mainstream journalists working together such as the Guardian Sports Network, which publishes select blogs and bloggers under a revenue-sharing scheme (McEnnis 2017). However, the professional-amateur relationship is also considered in the frame of a dominantsubordinate dynamic (Dart 2009). Journalists are asked during these sessions whether these relationships with bloggers are inclusive or exploitative.

Another potential riposte to the toy department label is to consider whether sports journalists are using digital tools to produce more serious stories. For instance, Freedom of Information ${ }^{2}$ requests have proved to be effective in sports contexts in the United Kingdom in recent years, such as the London Legacy Development Corporation (LLDC) being forced to disclose details of the Olympic Stadium rental deal with Premier League club West Ham (Gibson 2015) and Sussex Police in breach of the Fol Act over its handling of requests to explain claims that Crystal Palace supporters were armed with 'knives and knuckledusters' at a game against Brighton (Fifield 2018). However, as McEnnis (2018a) observes, these Fol requests tend to emerge from grassroots movements among supporter groups, rather than professional sports journalists. The West HamOlympic Stadium Fol request came from a coalition of 15 supporters' groups, while the Sussex Police FoI requests were submitted by the Crystal Palace fanzine Five-Year Plan. The course asks how sports journalists can contribute in this area to enhance their professional practice.

The programme then moves into investigative journalism more generally and enquires whether sports journalists can make a substantive commitment to it. Previous research has noted that investigative journalism work in sport tends to be conducted by specialist, news-based units and sports journalists find this convenient because it does not impact negatively on source relations (Boyle 2006). This argument has been evidenced in journalism in the United Kingdom recently with The Telegraph investigations team effectively ending the short reign of Sam Allardyce as England manager through a 'sting' operation (Anon 2016). Sky Sports News journalists consider their relationship with colleagues in Sky News towards investigative journalism. The course also explores how investigative journalism has become increasingly networked in character through the global collaborations on the Panama and Paradise Papers off-shore revelations and the BBC and Buzz Feed tennis match-fixing investigation, which Rowe (2017) has identified as a potentially fruitful collaborative model for sports journalists to pursue in future.

Industry professionals also explore the legal, ethical, regulatory, and editorial dimensions to investigative journalism - particularly in areas such as secret filming, deception, and subterfuge - with a view to instilling confidence and knowledge in pursuing this type of journalism. The course also considers how suspected computer hacking has increasingly set the news agenda through sources such as Football Leaks and Fancy Bears. Journalists on the course are asked whether this constitutes a form of investigative journalism and what is the ethical position of the mainstream media in verifying and reporting on the leaked information? 
The third and final section of the course focuses on contextual knowledge with the aim of providing greater depth to sports journalists' storytelling. A key aspect of this section is asking industry professionals how they can report with greater social responsibility in mind.

Weedon et al (2016) observe that academic concerns with what constitutes sports journalism include contextualized reporting, equitable coverage, equitable newsroom representation, and socially responsible and educative coverage. The course looks at work on diverse and minority groups within sports journalism, specifically gender (Franks and O'Neill 2016) and race (Farrington et al 2012). Sports journalists also explore how they can report responsibly and mitigate against unconscious bias in considering guidance issued to the media by mental health organizations and groups that promote equality and diversity. The course considers responsible reporting on disability sport by reviewing the guidance offered by the Activity Alliance (previously the English Federation of Disability Sport).

The section also covers political history and how it intersects with sport. As a broadcaster in the United Kingdom, SSN finds itself often reporting on sectarian issues in Scotland between the Rangers and Celtic football teams. Learning the background and history to these areas puts SSN journalists in a more informed position to cover the stories effectively (Bradley 2015). Another focus here is Ireland and understanding why football has two national teams (Northern Ireland and Republic of Ireland) while the rugby team has one. Sky Sports is a rights holder to the Gaelic Games so understanding the historical and political context is imperative to covering these sports insightfully (Bairner 2005; Cronin 1999).

Industry professionals also learn about how governance in sport works both at NGB and ISF level. They explore governmental interference through the Department of Digital, Culture, Media and Sport (DCMS) and its two main agencies UK Sport (elite sport) and Sport England (grassroots sport). The pros and cons of the elite programme are discussed and whether governing bodies and leagues, such as the England \& Wales Cricket Board (ECB) and the Premier League, are doing enough with the Sky TV money for live sports rights to invest in grassroots sport. Another area of governance is the role of law when it comes to sport. The pseudo-legal framework of sport is discussed through the role of Court of Arbitration of Sport (CAS). Recent rulings are discussed and the intersection of science and human rights is examined through cases such as Caster Semenya.

The cohorts consider how English law has intersected with sport particularly through its legislative focus on controlling football crowds since the 1960s (James 2017). The focus then turns to EU law and the impact of the Bosman ruling on the football world and the Kolpak ruling on English county cricket and its relationship with South African players in particular. Industry professionals 
also learn about competition law, as they relate to media and sports ownership, and intellectual property as it relates to image rights. The classes debate what leaving the European Union may mean for sport in the United Kingdom with a view to identifying key news lines.

Boyle (2006) has argued there has never been a greater need for inquiring journalism because of the hyper-commercialized nature of the professional sports environment. Sports business is a key aspect of this with the financial affairs of football clubs in particular needing detailed scrutiny. Candidates are equipped with the ability to report effectively on sports business issues by understanding the basics on how to read balance sheets and annual accounts. Industry professionals also critically examine financial play rules and whether its regulations and punishments are proving to be a deterrent to over-spending.

The course concludes with special themed sessions on Olympics and the FIFA. The Olympics class considers how the IOC is organized and its funding distribution model. It also explores key Olympic Games such as 1968 Mexico, 1936 Berlin, 1972 Munich, Los Angeles 1984 and contemplates their legacy on the Olympic movement and how this history informs contemporary developments. The political dimension of the Games is discussed with the corruption scandal of the Salt Lake City Winter Games in 2002 a key case study. The legacy of the Games, their impact on communities and resistant movements are also interrogated (Boykoff 2016). IOC reforms are analyzed to establish whether they are having a positive impact and have led to more transparent decision-making processes. Key news lines looking ahead to future Olympic Games, specifically Tokyo 2020, are explored.

The FIFA session is devised on similar lines. Candidates explore how FIFA is organized and structured and consider its history, with particular focus on the 2015 corruption scandal. They evaluate whether the reforms that FIFA have put in place are working and whether president Gianni Infantino has successfully changed the culture of FIFA. The investigative journalism of Andrew Jennings (2016) and The Sunday Times insight team of Heidi Blake and Jonathan Calvert (2016) combined with the investigative sociology of Alan Tomlinson and John Sugden (2016) is particularly useful in informing the learning in the session. The industry professionals identify some of the reporting issues ahead of Qatar 2022 and consider talking points around the awarding of the 2026 World Cup to a joint bid of USA, Canada and Mexico.

\section{Critical reflections}

A key strength of the academic development programme is that it gives candidates vital breathing room within a hectic 24-hour rolling news work environment to pause and reflect upon their professional practice. It also enables industry professionals to come together from disparate departments within a large organization and discuss experiences, challenges, and examples of good practice with colleagues. 
Ultimately, the formal learning on the course is designed to raise professional standards in sports journalism within the organization. It is not concerned with the technical skills of being a broadcast journalist. The course instead aims to develop expertise in journalism through greater understanding of the profession and industry, sense making of how the occupation has been transformed by digital technology, heightened awareness of social responsibility, greater political awareness and the acquisition of contextual knowledge.

The academic development programme is best situated within the concept of professionalism. Salwen and Garrison (1998) found that professionalism is one of the key concerns of sports journalists who were troubled by their 'toy department' reputation. The academic development programme can therefore be seen as part of the professionalization of sports journalism. SSN recognizes that higher professional standards will lead to better journalism. The award of the Certificate in Professional Sport Journalism for passing the course helps to credentialize the industry professionals within the organization. The academic development programme also contributes towards destigmatizing journalism as an academic subject. The fact that a major news organization is prepared to learn from academic sets a benchmark standard for the rest of the industry.

There are also significant benefits for the university. The course provides invaluable insights into the broadcast sport journalism environment that can inform curriculum development and course content for undergraduate and postgraduate students. The partnership with Sky has also led to other initiatives, such as a Women in Sports Media conference (University of Brighton 2016) that invited schools from the area to engage with female industry professionals through a keynote talk, workshop sessions, and a question-and-answer session. The aim of the conference was to change perceptions of sports media as being a career for men and is a format that has since been adopted by other universities within the United Kingdom.

\section{Conclusion}

This article has provided an exposition of how an academic learning programme has been constructed for industry professionals with a view to improving journalistic standards. It is hoped that in raising awareness it can be a catalyst for more constructive and forward thinking partnerships between sports journalism education and industry across different contexts and countries.

However, there are challenges and constraints that need to be overcome. Not many news organizations have the financial power of Sky. Whether it can be a catalyst for similar arrangements remains to be seen. The question of whether the course can be adopted more widely is open to debate. While the broadcast media business is in rude health, as evidenced by the Comcast takeover, the print media is struggling financially. However, the opening paragraphs of this article suggest that what will prevent it is as much an issue of culture and attitude as the balance sheet. Another problematic area is how the journalist-student reconciles the time and commitments of part-time study with performing a demanding full- 
time job. There is a need to be mindful and watchful about the potential impacts on stress levels and mental health on the individual.

Finally, it is difficult to measure and quantify the impact of the programme on sports journalists' professional practice. Testimonials and anecdotal evidence from both the journalist-student and editorial managers are, at the time of writing, being sourced and potentially provide scope for a future follow-up article.

\section{Notes}

${ }^{1}$ Sky operates 11 sports channels, including Sky Sports News. At the time of writing, the other channels are Sky Sports Main Event, Sky Sports Premier League, Sky Sports Football, Sky Sports Cricket, Sky Sports Golf, Sky Sports Racing, Sky Sports F1, Sky Sports Action, Sky Sports Arena and Sky Sports Mix.

${ }^{2}$ The Freedom of Information Act 2000 in England and Wales created a 'right to access' information held by public bodies to ensure greater accountability and transparency.

\section{References}

Aldridge, Meryl and Evetts, Julia (2003), 'Rethinking the concept of professionalism: The case of journalism', British Journal of Sociology, 54:4, pp. 547-564.

Anon. (2014), 'How much journalism training was there at The Sun? 'None', former managing editor Graham Dudman tells court', Press Gazette, December 2, https://www.pressgazette.co.uk/how-much-journalism-training-was-there-sunnone-former-managing-editor-graham-dudman-tells-court/. Accessed 5 July 2019.

Anon. (2016) 'Exclusive investigation: England manager Sam Allardyce for sale', Daily Telegraph, 27 September, https://www.telegraph.co.uk/news/2016/09/26/exclusive-investigationengland-manager-sam-allardyce-for-sale/. Accessed 5 July 2019.

Bairner, Alan (2005), Sport and the Irish: Histories, Identities, Issues, Dublin: University College Dublin Press.

Blake, Heidi and Calvert, Jonathan (2016), The Ugly Game: The Qatari Plot to Buy the World Cup, London: Simon \& Schuster.

Boykoff, Jules (2016), Power Games: A Political History of the Olympics, London: Verso.

Boyle, Raymond (2006), Sports Journalism: Context and Issues, London: Sage. (2010), 'Sport and the media in the UK: the long revolution?', Sport in Society, 13:9, pp.1300-1313. 
Boyle, Raymond and Haynes, Richard (2004), Football in the New Media Age, Abingdon: Routledge.

(2009) Power Play: Sport, the Media and Popular Culture (2 ${ }^{\text {nd }}$ edition), Edinburgh: Edinburgh University Press.

Bradley, Joseph M (2015) 'Sectarianism, anti-sectarianism and Scottish football', Sport in Society, 18:5, pp. 588-603.

Cassidy, William P (2017), 'Inching Away From the Toy Department: Daily Newspaper Sports Coverage of Jason Collins' and Michael Sam's Coming Out', Communication \& Sport, 5:5, pp. 534-553.

Cronin, Michael G (1999), Sport and Nationalism in Ireland: Gaelic Games, Soccer and Irish Identity Since 1884, Dublin: Four Courts Press.

Dart, Jon (2009), 'Blogging the 2006 World Cup Finals', Sociology of Sport Journal, 26:1, pp. 107-126.

Dowling, David and Vogan Travis (2015), 'Can we "Snowfall” this? Digital longform and the race for the tablet market', Digital Journalism, 3:2, pp. 209-224.

English, Peter (2011), 'Online versus print: A comparative analysis of web-first sports coverage in Australia and the United Kingdom'. Media International Australia, 140:1, pp. 147-156.

Farrington, Neil, Kilvington, Daniel, Price, John, and Saeed, Amir (2012), Race, Racism and Sports Journalism, Abingdon: Routledge.

Fifield, Dominic (2018), 'Sussex police breach FoI act after Crystal Palace fans take action', The Guardian, 22 August, https://www.theguardian.com/football/2018/aug/22/sussex-police-breach-foicrystal-palace-fans. Accessed 5 July 2019.

Franks, Suzanne and O’Neill, Deirdre (2016), 'Women reporting sport: Still a man's game?' Journalism, 17:4, pp. 474-492.

Gibson, Owen (2015), 'Details of West Ham's Olympic Stadium deal must be made public', The Guardian, 15 September, https://www.theguardian.com/football/2015/sep/15/west-ham-detailsolympic-stadium-deal. Accessed 5 July 2019.

Haynes, Richard (1995), The Football Imagination: Rise of Football Fanzine Culture, Farnham: Ashgate Publishing.

Hutchins, Brett and Boyle, Raymond (2017), 'A community of practice: Sport journalism, mobile media and institutional change' Digital Journalism, 5:5, pp. 496-512 
Hutchins, Brett and Rowe, David (2012), Sport Beyond Television: The Internet, Digital Media and the Rise of Networked Sport. London: Routledge.

James, Mark (2017), Sports Law (3rd edition), London: Palgrave Macmillan.

Jennings, Andrew (2016), The Dirty Game: Uncovering the Scandal at FIFA, London: Arrow Books.

Ketterer, Stan, McGuire, John, and Murray, Ray (2014), 'Contrasting desired sports journalism skills in a convergent media environment', Communication \& Sport, 2:3, pp. 282-298.

McEnnis, Simon (2016), 'Following the action: How live bloggers are reimagining the professional ideology of sports journalism', Journalism Practice, 10:8, pp. 967-982.

(2017), 'Playing on the same pitch: Attitudes of sports journalists towards fan bloggers', Digital Journalism, 5:5, pp. 549-566.

(2018a), 'Sports journalism and cultural authority in the digital age', in T.F. Carter, D. Burdsey and M. Doidge (eds), Transforming Sport: Knowledges, Practices, Structures, Abingdon: Routledge, pp. 207-220.

(2018b), 'Toy department within the toy department? Online sports journalists and professional legitimacy', Journalism, September, https://journals.sagepub.com/doi/abs/10.1177/1464884918797613. Accessed 5 July 2019.

Morrison, Sara (2014), 'The toy department shall lead us: Why sports media have always been newsroom innovators', Columbia Journalism Review, July/August, https://archives.cjr.org/reports/the_toy_department_shall_lead.php. Accessed 5 July 2019.

Oates, Thomas P and Pauly, John (2007), 'Sports journalism as moral and ethical discourse', Journal of Mass Media Ethics, 22:4, pp. 332-347.

Ponsford, Dominic (2016), 'Sun editor Tony Gallagher on Brexit, journalism as a trade not profession and how the BBC never breaks stories', Press Gazette, March 2, https://www.pressgazette.co.uk/sun-editor-tony-gallagher-brexit-journalismtrade-not-profession-and-how-bbc-never-breaks-stories. Accessed 5 July 2019.

Rowe, David (2004), Sport, Culture and the Media (2 ${ }^{\text {nd }}$ ed), Buckingham: Open University Press.

(2007), 'Sports journalism: Still the 'toy department' of the news media?' Journalism, 8:4, pp. 385-405. 
(2017), 'Sports journalism and the FIFA scandal: Personalization, cooptation and investigation'. Communication \& Sport, 5:5, pp. 515-533.

Salwen Michael B and Garrison Bruce (1998), 'Finding their place in journalism: Newspaper sports journalists' "professional problems"', Journal of Sport \& Social Issues, 22:1, pp. 88-102.

Sherwood, Merryn, and Nicholson, Matthew (2013), 'Web 2.0 platforms and the work of newspaper sport journalists', Journalism, 14:7, pp. 942-959.

Sherwood, Merryn, Nicholson, Matthew, and Marjoribanks, Tim (2017a), 'Access, agenda building and information subsidies: Media relations in professional sport', International Review for the Sociology of Sport, 52:8, pp.992-1007

(2017b), 'Controlling the

message and the medium? The impact of sports organisations' digital and social channels on media access', Digital Journalism, 5:5, pp. 513-531

Sugden, John and Tomlinson, Alan (2007), 'Stories from planet football and sportsworld: Source relations and collusion in sport journalism', Journalism Practice, 1:1, pp. 44-61.

(2010), 'What Beckham had for breakfast: The rolling menu of 24/7 sports news', in J. Lewis and S. Cushion (eds), The Rise of 24-hour News Television: Global Perspectives, Oxford: Peter Lang, pp. 151-166.

(2016), Football, Corruption and Lies.

Revisiting Badfellas, the Book FIFA Tried to Ban. Abingdon: Routledge.

Suggs Jr, David W (2015), 'Tensions in the press box: Understanding relationships among sports media and source organizations', Communication \& Sport, 4:3, pp. 261-281.

University of Brighton (2016), 'Sky's the limit for women in sports media', https://www.brighton.ac.uk/about-us/news-and-events/news/2016/03-21sky\%27s-the-limit-for-women-in-sports-media.aspx. Accessed 5 July 2019.

Waterson, Jim (2018), 'Sky takeover: Murdoch must offload Sky News to get green light', The Guardian, 5 June, https://www.theguardian.com/business/2018/jun/05/sky-takeover-murdochsky-news-uk-fox-comcast. Accessed 5 July 2019.

Weedon, Gavin, Wilson, Brian, Yoon, Liv, and Lawson, Shawna (2016), 'Where's all the 'good' sports journalism? Sports media research, the sociology of sport, and the question of quality sports reporting', International Review for the Sociology of Sport, 53:6, pp. 639-667. 
Wenner, Lawrence (1998), MediaSport, London: Routledge.

Whannel, Garry (1992), Fields in Vision: Television Sport and Cultural

Transformation, London: Routledge.

Ends

Word count: 5,887 